\title{
Tomada de decisão de controle da traça-do-tomateiro através de armadi- lhas com feromônio sexual
}

\author{
Sérgio Roberto Benvenga ${ }^{1}$; Odair Aparecido Fernandes ${ }^{2}$; Santin Gravena ${ }^{1}$ \\ ${ }^{1}$ Gravena ManEcol Ltda, C. Postal 546, 14870-990 Jaboticabal-SP; ${ }^{2}$ UNESP, FCAV Depto. Fitossanidade, Rod. Prof. Paulo D. Castellane \\ km 5, 14884-900 Jaboticabal-SP; srbenvenga@gravena.com.br; oafernandes@fcav.unesp.br
}

\section{RESUMO}

Visou-se estabelecer a relação entre a infestação da traça-dotomateiro, Tuta absoluta, na planta e adultos capturados em armadilhas com feromônio sexual e a produtividade, para avaliar a influência da infestação na produção da cultura do tomate e aperfeiçoar a tomada de decisão de controle pela densidade de adultos. Armadilhas com feromônio sexual foram instaladas e avaliadas duas vezes por semana, em três áreas de cultivo comercial de tomateiro em São Paulo (Mogi-Guaçu, Tambaú e Sorocaba), em sistema estaqueado, divididas em áreas experimentais com cerca de 18.000 plantas cada (1,5 ha). Nas mesmas datas foi avaliada a infestação de pragas nas plantas, estendendo-se até o término da colheita. A produtividade foi definida pelo total de caixas ( $24 \mathrm{~kg}$ ) comercializadas/1.000 plantas. A relação entre a produção da cultura do tomate e a infestação de T. absoluta na planta ou nas armadilhas com feromônio foi expressa por uma equação linear e negativa. A ocorrência de adultos nas armadilhas e a infestação da praga em plantas foram relacionados significativamente com a redução da produtividade. O nível de controle de T. absoluta através do monitoramento com feromônio sexual foi de $45 \pm 19,50$ insetos/dia na armadilha.

Palavras-chave: Tuta absoluta, Lycopersicon esculentum, monitoramento, nível de controle.

\section{ABSTRACT}

Decision making for integrated pest management of the South American tomato pinworm based on sexual pheromone traps

The relationship between the productivity and the infestation of Tuta absoluta on tomato plants and adults caught in sexual pheromone traps was established to evaluate the effect of pest infestation on yield losses as well as on adults' density for decision-making improvement. Sexual pheromone traps were installed in three commercial fields of tomato in São Paulo State, Brazil (Mogi Guaçu, Tambaú and Sorocaba counties) with experimental plots of 18,000 plants each (1.5 ha). The presence of insects in the traps as well as the infestation on plants were evaluated twice a week on the same dates. The evaluations took place until harvesting. The productivity was expressed as marketable boxes of $24 \mathrm{~kg} / 1000$ plants. The relationship between tomato production and pest infestation on plants or pheromone traps was linear and negative. The adults' occurrence on traps and plant infestation showed an influence on yield losses. The action level of T. absoluta with sexual pheromone traps was 45 \pm 19.50 insects daily.

Keywords: Tuta absoluta, Lycopersicon esculentum, monitoring, action level.

(Recebido para publicação em 15 de janeiro de 2006; aceito em 2 de maio de 2007)

A traça-do-tomateiro, Tuta absoluta Meyrick) (Lepidoptera: Gelechiidae), é um dos principais lepidópteros-praga na cultura do tomate, devido ao potencial de infestação nas folhas, ramos terminais e frutos, com redução da produção destinada ao comércio e indústria (Haji et al., 1988). Assim, além de afetar indiretamente a produção pela redução de área foliar, concorre diretamente para a redução de produtividade por inutilizar os frutos (Gravena, 1991; Picanço et al., 1997).

As infestações da traça-do-tomateiro são mais intensas no período de frutificação da cultura, pois as lagartas ao permanecerem no interior dos frutos não são afetadas pelas ações de controle. Com isso, ocorre a emergência de adultos e a reinfestação das partes vegetativas e reprodutivas das plantas (Gravena, 1991).

O controle químico é a principal tática de manejo desta praga nas regiões produtoras (Souza et al., 1992). As aplicações e as misturas de inseticidas na cultura do tomate são programadas em função do estágio fenológico favorável ao ataque das pragas (Gravena \& Benvenga, 2003). Nos cultivos comerciais, em casos extremos, são realizadas até 36 aplicações de inseticidas durante o ciclo da cultura para o controle de T. absoluta e de outros artrópodes pragas (Souza et al., 1992).

O sistema preventivo de controle fitossanitário, além de onerar o custo de produção, aumenta os riscos de intoxicação dos aplicadores e de contaminação do meio ambiente. O consumidor final também pode ser indiretamente afetado pela depreciação da qualidade nutricional do alimento, contendo resíduos acima dos limites toleráveis para o consumo (Gravena, 1984). Além disso, a constante pressão de seleção exercida pelos inseticidas tem favore- cido o desenvolvimento de populações de pragas resistentes (Omoto, 2000).

O manejo integrado de pragas apresenta como uma de suas bases a amostragem de pragas pois, definindose as espécies e os respectivos índices de infestação, torna-se possível uma definição mais criteriosa das táticas de controle. Gravena \& Benvenga (2003) sugerem que nos cultivos em sistema de manejo integrado seja feita a amostragem de ovos e lagartas da traça-do-tomateiro nas partes vegetativas e reprodutivas das plantas.

Picanço et al. (1995) ressaltam a importância da amostragem de ovos da traça-do-tomateiro, pois a eficiência dos inseticidas é maior antes da penetração da praga no interior dos órgãos da planta. Gomide et al. (2001) comentam que o monitoramento de ovos é vantajoso, pois além de ser o primeiro indício da presença da praga na planta, torna-se 
possível o uso isolado de inseticidas biológicos visando o controle de lagartas recém eclodidas ainda nesta fase de maior vulnerabilidade.

A técnica de amostragem de pragas na cultura do tomate já é consolidada na pesquisa e está em desenvolvimento nos cultivos comerciais. Entretanto, o nível de detalhamento exigido para a amostragem da traça-do-tomateiro em plantas é o principal ítem que define o rendimento do inspetor de pragas em campo. Portanto, novas tecnologias devem ser pesquisadas, como a utilização de armadilhas contendo o feromônio sintético para a amostragem do nível populacional de insetos (Bento, 2000). Esta estratégia visa estabelecer métodos rápidos, práticos e confiáveis, valorizando sobremaneira o manejo integrado de pragas. Na cultura do tomate as armadilhas podem ser empregadas para determinar a migração de adultos da traça-dotomateiro (Vilela et al., 1995; Eiras et al., 1995; Vilela, 1997). A fase adulta é considerada como o primeiro indício da presença da praga na cultura, favorecendo a ação dos inseticidas e dinamizando as tomadas de decisão de controle.

Bento (2000) ressalta que os estudos que correlacionam o número de insetos capturados na armadilha e a infestação da praga na planta são de grande valia para que medidas de controle sejam tomadas, a fim de se evitar ou reduzir danos. Entretanto, para a traça-do-tomateiro os estudos com feromônio sexual concentraram-se apenas na avaliação de atratividade de machos em condições de cultivo protegido (Guedes et al., 1996) e campo (Uchoa-Fernandes \& Vilela, 1994; Gomide et al., 2001).

O presente trabalho teve por objetivo estabelecer a relação entre a infestação da traça-do-tomateiro, Tuta absoluta, na planta, bem como o número de adultos capturados em armadilhas contendo feromônio sexual, com a produtividade. Esta estratégia permitirá avaliar a influência da infestação na produção da cultura do tomate e aperfeiçoar a tomada de decisão de controle pela densidade de adultos.

\section{MATERIAL E MÉTODOS}

O estudo foi realizado em três áreas de cultivo comercial de tomate, em siste- ma estaqueado de condução com fileiras duplas, sendo divididas em áreas experimentais retangulares, com número aproximado de 18.000 plantas, equivalendo a uma área de 1,5 ha, durante o ciclo de inverno do ano de 2002 (Tabela 1).

Para o monitoramento de adultos, em cada área experimental, foram instaladas nos vértices opostos duas armadilhas do tipo Delta com septo de látex impregnado com feromônio sexual ISCAlureTUTA ${ }^{\circledR}$ (ISCA Tecnologias Ltda, Ijuí, RS). As armadilhas foram fixadas em haste de bambu de modo a manter a altura cerca de vinte centímetros acima das plantas. Portanto, de acordo com o estágio fenológico, as armadilhas eram movidas verticalmente. Os septos com o feromônio foram substituídos mensalmente e os fundos descartáveis em intervalos quinzenais após a instalação das armadilhas. Os insetos capturados nas armadilhas foram contados e retirados com o auxílio de uma pinça em intervalos de três a cinco dias.

$O$ índice de infestação da traça-dotomateiro foi obtido em 60 plantas de cada área experimental em avaliações realizadas nas mesmas datas em que houve verificação das armadilhas, sendo que foram amostrados 12 pontos de cinco plantas consecutivas (Gravena, 1991). Os pontos foram escolhidos aleatoriamente. As folhas em desenvolvimento no ponteiro foram avaliadas visualmente para a detecção de ovos (Haji et al., 1998; Gomide et al., 2001), além do ramo apical para a detecção de lagartas (Espinosa, 1991). No terço mediano foi avaliada uma folha com sintoma de ataque para a detecção de lagartas vivas (Rego Filho, 1992; Moreira et al., 1997; Gomide et al., 2001). As pencas contendo frutos com diâmetro médio de dois centímetros foram avaliadas para a detecção de ovos, sintomas de ataque e infestação por lagartas. Todas as avaliações foram conduzidas até a colheita.

Nas três localidades a colheita foi realizada separadamente em cada área experimental. A produtividade de cada área foi expressa em caixas de $24 \mathrm{~kg}$ de tomate comercial/1000 plantas cultivadas, desconsiderando-se a classificação final.
Os dados de produtividade de cada área experimental e os respectivos índices de infestação de T. absoluta no ponteiro, folha e fruto foram submetidos à análise de regressão linear utilizandose o procedimento PROC REG (SAS Institute, Cary, NC, USA). Os índices de infestação nas partes vegetativas e reprodutivas foram acumulados diariamente, para expressão simultânea da intensidade e duração da infestação, conforme a metodologia proposta por Ruppel (1983). A terminologia de inseto-dia é recomendada para estudos de manejo de pragas com controle químico, pois representa através de uma única equação a combinação entre a densidade de indivíduos remanescentes da pulverização e o período em que ainda permaneceram ativos.

\section{Controle da população de artrópodes pragas}

Com a determinação dos índices de infestação foi estabelecido o controle químico nas áreas experimentais quando os índices médios atingiam $5 \%$ de plantas com presença de ovos nos frutos ou $25 \%$ de plantas com ovos ou lagartas no ponteiro ou $25 \%$ de plantas com lagartas nas folhas do terço mediano. Inseticidas de grupos químicos diferentes foram trocados a cada aplicação e preconizou-se a mistura de inseticidas (Omoto, 2000). Os princípios ativos utilizados foram: abamectin, alphacypermethrin, cartap, chlorfluazuron, chlorfenapyr, chlorpyrifos, fenpropathrin, indoxacarb, lambdacyhalothrin, lufenuron, methoxifenozide, spinosad e triflumuron.

O controle do complexo de vetores constituído por tripes, Frankliniella spp. (Thysanoptera: Thripidae), pulgão, Myzus sp. (Hemiptera: Aphididae) e mosca branca, Bemisia tabaci Gennadius (Hemiptera: Aleyrodidae) foi realizado quando a infestação atingia o número médio de um inseto/planta (Gravena, 1991).

\section{RESULTADOS E DISCUSSÃO}

\section{Relação entre a infestação na plan- ta e a produtividade}

As infestações da traça-do-tomateiro no ponteiro, folha e no fruto resulta- 
Tabela 1. Especificações das áreas experimentais em cultivos comerciais de tomate estaqueado sob o sistema de manejo integrado de pragas (Details of the experimental áreas of staked tomato commercial crop, under the system of integrated pest management).

\begin{tabular}{llll}
\hline Local & Mogi Guaçu, SP & Tambaú, SP & Sorocaba, SP \\
\hline Propriedade & Fazenda Urutuba & Fazenda Barreiro & Fazenda Alteza \\
Localização & $22^{\circ} 14,750^{\prime}$ S & $21^{\circ} 34,294^{\prime}$ S & $23^{\circ} 28,556^{\prime}$ S \\
Altitude $(m)$ & $46^{\circ} 56,590^{\prime}$ WO & $47^{\circ} 10,198^{\prime}$ WO & $47^{\circ} 31,433^{\prime}$ WO \\
Híbrido & 638 & 622 & 610 \\
Área cultivada (ha) & Fanny & Carmen & Débora \\
$\mathrm{N}^{\circ}$ plantas & 16,0 & 13,5 & 18,7 \\
$\mathrm{~N}^{\circ}$ áreas experimentais & 192.000 & 165.000 & 224.500 \\
$\mathrm{~N}^{\circ}$ médio plantas/área & 11 & 8 & 13 \\
$\mathrm{~N}^{\circ}$ armadilhas feromônio & 17.450 & 20.625 & 17.269 \\
$\mathrm{~N}^{\circ}$ armadilha:planta & $1: 8.725$ & 182 & 26 \\
Data transplantio & $31 / 5 / 2002$ & $1: 9.165$ & $1: 8.634$ \\
Início da amostragem & $27 / 6 / 02$ (27 DAT1) & $1 / 7 / 2002$ & $9 / 8 / 2002$ \\
Término da amostragem & $30 / 9 / 02$ (122 DAT) & $7 / 8 / 02(37$ DAT) & $9 / 9 / 02(31$ DAT) \\
$\mathrm{N}^{\circ}$ de avaliações & 18 & $6 / 11 / 02(128$ DAT) & $9 / 12 / 02(122$ DAT) \\
Avaliação atividade de vôo & $12 / 7 / 02$ (42 DAT) & 19 & 27 \\
\hline
\end{tabular}

${ }^{1}$ DAT: Dias após o transplantio das mudas (Days after transplanting); ${ }^{2} \mathrm{Em}$ uma das áreas experimentais foram adicionadas duas armadilhas, para adequar a relação armadilha:planta (In one of the áreas it was added two more traps, to adequate the relation trap:plant).

Tabela 2. Parâmetros da análise de regressão linear entre os tipos de infestação de Tuta absoluta acumulados diariamente e a produtividade da cultura do tomate (Parameters of the linear regression analysis between the types of infestation of Tuta absoluta accumulated daily and tomato yield). Jaboticabal, Gravena Man Ecol, 2002.

\begin{tabular}{llrrrr}
\hline Infestação & Equação da Regressão Linear & $\mathbf{R}^{\mathbf{2}}$ & $\mathbf{F}$ & $\mathbf{d f}$ & $\mathbf{P}$ \\
\hline Ovo-Dia Ponteiro & $\mathrm{y}=-1,5822 * 10^{-2} \mathrm{x}+204,768264$ & 0,2716 & 11,185 & 1,30 & 0,0022 \\
Lagarta-Dia Ponteiro & $\mathrm{y}=-5,8325 * 10^{-2} \mathrm{x}+189,525459$ & 0,2355 & 9,243 & 1,30 & 0,0049 \\
Sintoma-Dia Folha & $\mathrm{y}=-9,375 * 10^{-3} \mathrm{x}+194,777690$ & 0,1775 & 6,474 & 1,30 & 0,0163 \\
Lagarta-Dia Folha & $\mathrm{y}=-1,4063 * 10^{-2} \mathrm{x}+192,201379$ & 0,1703 & 6,159 & 1,30 & 0,0189 \\
Ovo-Dia Fruto & $\mathrm{y}=-7,2938 * 10^{-2} \mathrm{x}+213,347449$ & 0,4188 & 21,616 & 1,30 & 0,0001 \\
Sintoma-Dia Fruto & $\mathrm{y}=-3,8964 * 10^{-2} x+215,605346$ & 0,5825 & 41,858 & 1,30 & 0,0001 \\
Lagarta-Dia Fruto & $\mathrm{y}=-6,1977 * 10^{-2} \mathrm{x}+208,976859$ & 0,4908 & 28,911 & 1,30 & 0,0001 \\
\hline
\end{tabular}

ram numa relação linear e negativa com a produtividade da cultura do tomate nas três áreas experimentais (Tabela 2). Segundo Haji et al. (1988), a infestação da traça-do-tomateiro pode ser verificada nas plantas durante todo o ciclo de desenvolvimento, sendo mais intensa no período de frutificação, devido à menor eficiência das ações de controle sobre as lagartas no interior dos frutos, concorrendo diretamente para a redução da produtividade. Entretanto, a infestação sobre as partes vegetativas afeta indiretamente a produção pela redução de área foliar (Gravena, 1991). Portanto, a contribuição deste trabalho está relacionada ao detalhamento da infestação de T. absoluta em ramos, folhas e frutos, respectivamente, e a influência sobre a produtividade da cultura do tomate.
Os parâmetros relacionados à infestação da praga na folha, definidos como sintoma-dia e lagarta-dia acumulados na folha, resultaram nos menores coeficientes de determinação (Tabela 2). Deste modo, indicaram que exercem uma menor influência sobre a redução de produtividade da cultura quando comparado com a infestação no ponteiro e nos frutos. Como a avaliação da infestação da traça-do-tomateiro foi realizada nas folhas do terço mediano, consideradas ideais segundo Rego Filho (1992), Moreira et al. (1997) e Gomide et al. (2001), os resultados obtidos na análise de regressão linear podem ser compreendidos considerando-se a atividade fotossintética destas folhas e o hábito de migração das lagartas. No terço mediano, devido à alta concentração de folhas, pode haver competição por luminosidade e somente aquelas localizadas mais externamente à planta apresentam maior atividade fotossintética. As folhas infestadas foram constatadas mais internamente na planta devido, provavelmente, à menor ação do inseticida. Esta infestação não afetou expressivamente a fotossíntese e, conseqüentemente, a produtividade. Outro fator a ser considerado é a movimentação de lagartas sobre as folhas após o segundo ínstar, conforme mencionado por Haji et al. (1988). Este comportamento pode estar relacionado ao aumento de temperatura no interior da mina exposta ao sol, acúmulo de excrementos ou mesmo pela depreciação do alimento (Torres et al., 2001). Deste modo, mesmo sendo observadas nas folhas, devido ao compor- 


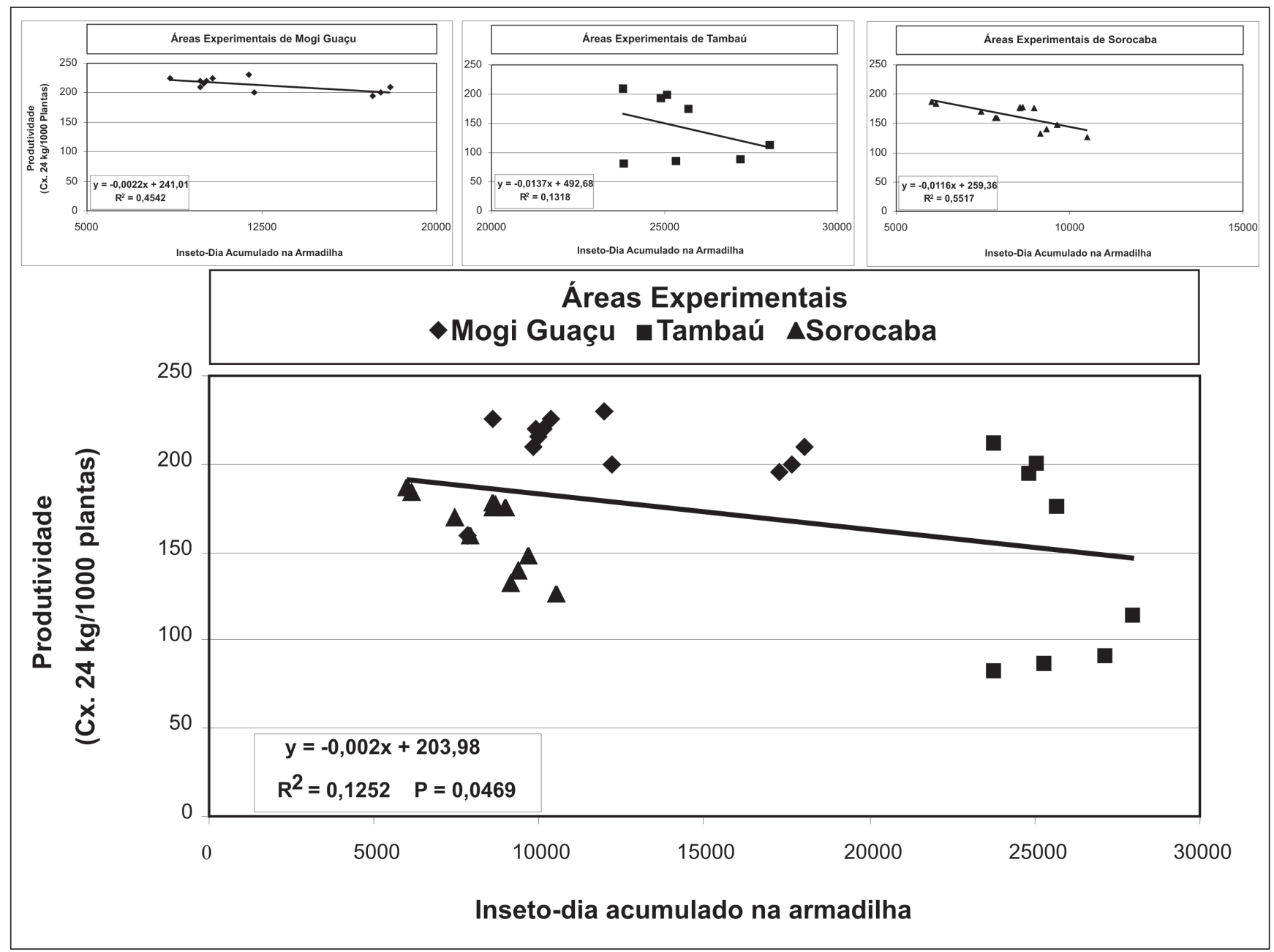

Figura 1. Regressão linear entre a ocorrência de adultos de Tuta absoluta, acumulados diariamente em armadilhas com feromônio e a produtividade da cultura do tomate (Linear regression among the occurrence of Tuta absoluta adults, accumulated daily in traps with pheromon and tomato yield).

tamento de migração das lagartas, algumas podem ter se dirigido para os frutos. A redução na produtividade causada pelas lagartas foi maior pelo dano direto (perda de frutos), do que pela injúria causada às folhas (redução de área foliar).

A baixa influência da infestação nas folhas por lagartas de T. absoluta sobre a produtividade da cultura do tomate também foi ressaltada por Caffarini et al. (1999) ao verificarem elevado índice de frutos infestados mesmo com baixo índice de área foliar danificada; concluíram que as folhas não devem ser consideradas como indicadores do potencial de dano da praga.

A análise de regressão também foi realizada entre a infestação da praga no ponteiro, definidos como ovo-dia e lagarta-dia acumulados no ponteiro, apresentou coeficientes de determinação superiores aos verificados para a infestação na folha (Tabela 2). Esta maior influência da infestação no ponteiro sobre a produtividade da cultura pode ser justificada pelo modo de crescimento das plantas e hábito de oviposição da praga. A traça-do-tomateiro realiza a oviposição nas folhas tenras (Vargas, 1970; Haji et al., 1998; Gomide et al., 2001). O crescimento das plantas de tomate ocorre por intermédio do lançamento de novas folhas no ápice (Espinosa, 1991). Assim, no intervalo entre as pulverizações, essas folhas emitidas no ponteiro permanecem suscetíveis ao ataque da praga. Considerando-se o período médio de incubação dos ovos de 4,5 dias (Marques \& Alves, 1996) e a ocorrência de gerações superpostas da praga, ou seja, diariamente são depositados ovos nos tecidos tenros, a eclosão de lagartas é permanente, favorecendo a penetração destas nos ponteiros. Portanto, mesmo com um aumento na freqüência de pulverizações, devido à localização dos ovos, a pilosidade dos tecidos tenros e pouco conhecimento do efeito ovicida dos inseticidas, a intensidade de ramos infestados é dependente da qualidade de aplicação para que atinja o alvo com eficácia.

Após a eclosão das lagartas e a penetração nos ramos ponteiros, a eficiência de controle dos inseticidas é severamente afetada (Picanço et al., 1995). Os danos de T. absoluta, quando localizados no ramo ponteiro, resumem-se a uma super-brotação (Gravena \& Benvenga, 2003), devido à perda da dominância apical. Neste caso, o porte das plantas é severamente afetado, resultando na redução da produção pelo 
menor número de pencas no dossel das plantas.

Os maiores coeficientes de determinação foram verificados para os parâmetros referentes à infestação no fruto, considerando-se ovo-dia, sintomadia e lagarta-dia acumulados (Tabela 2). Resultado semelhante foi obtido por Picanço et al. (1997), em um experimento com a cultura do tomate no período de junho a setembro, em que a traçado-tomateiro foi considerada como o segundo fator mais importante para a redução da produtividade. Neste caso, a justificativa recai sobre o local de infestação da praga pois, com a presença de ovos nos frutos, as lagartas penetram e causam dano direto. Conseqüentemente os frutos infestados perdem o valor comercial para o mercado e indústria (Gravena, 1991), sendo descartados durante o processo de colheita. Isso afeta diretamente a produtividade da cultura.

A utilização dos parâmetros que consideraram os ovos da traça-do-tomateiro, definidos como ovo-dia acumulado no ponteiro e ovo-dia acumulado no fruto, permitiu inferência da redução da produtividade da cultura. Embora o ovo não seja uma fase da praga que ocasiona dano direto, a amostragem dessa fase e o controle das lagartas eclodidas permitiram a redução de possíveis prejuízos à produção. Com isso, a amostragem de adultos com armadilhas de feromônio pode permitir a identificação dos primeiros surtos populacionais de insetos migrantes e facilitar a definição das táticas de controle para o favorecimento do manejo de pragas nesta cultura, antes do início da oviposição.

Relação entre a densidade de adultos e produtividade

A influência da infestação de adultos de T. absoluta, definida pelo parâmetro de inseto-dia acumulado na armadilha com feromônio sobre a produtividade da cultura do tomate, foi expressa significativamente por uma equação linear e negativa (Figura 1).

Neste caso, como houve relação entre o parâmetro de inseto-dia acumulado na armadilha e a produtividade, é possível estimar a redução de frutos comercializados em função do número de insetos capturados e definir um nível de controle através da densidade de cap- tura. Assim, considerando-se o período de condução da cultura, definiu-se o número mínimo de insetos tolerados diariamente na armadilha para a obtenção da produtividade desejada. Estabelecendo-se uma produtividade média esperada de 267 caixas de $24 \mathrm{~kg} / 1.000$ plantas, equivalente a 3.200 caixas/ha, e um valor médio de comercialização igual a R\$ 10,07/caixa de $24 \mathrm{~kg}$ (taxa de conversão: US\$ $1=\mathrm{R} \$ 2,50$ ) ao longo dos meses do ano, com um custo de $\mathrm{R} \$$ 6,22/caixa (Agrianual, 2002), temse uma receita positiva de $\mathrm{R} \$ 3,85 /$ caixa. Deste modo, com os valores de venda e custo de produção, o produtor deve obter um volume mínimo comercializado de 191 caixas/1.000 plantas para garantir lucro estimado de $15 \%$. Com este valor de produtividade obteve-se o número de inseto-dia acumulado através da expressão $\mathrm{y}=-0,002$ $x+203,98$ (Figura 1), sendo o total de 6.278 insetos. O período de condução da cultura desde o transplantio até o término da colheita é, na maioria das regiões de cultivo, de aproximadamente 140 dias, de modo que diariamente seriam tolerados $45 \pm 19,50$ insetos capturados/armadilha com feromônio sexual para a obtenção dos referidos valores de produtividade e lucratividade. Este valor é referencial, pois foram consideradas as médias ao longo do ano, embora seja possível estabelecer níveis de controle a cada mês de cultivo em função do valor de comercialização do produto final. Além disso, foi considerada a equação para as três áreas experimentais, como efeito de variabilidade de parâmetros climáticos, níveis de infestação e tecnologia de condução da cultura. Assim, passa a ser referencial aos pesquisadores prosseguirem com estudos de correlação da T. absoluta em outras regiões de cultivo para a validação dos resultados e também aos técnicos, no sentido de incentivar o manejo integrado de pragas e racionalizar o uso dos defensivos agrícolas na cultura do tomate.

Através da amostragem da população de adultos de T. absoluta na armadilha com feromônio e a possibilidade de estimar o índice de ponteiros e frutos com ovos em função da produtividade, poderão ser avaliadas maneiras para a implementação do controle bio- lógico artificial. Nestes casos seriam programadas as liberações inundativas de Trichogramma spp. (Hymenoptera: Trichogrammatidae) em função da produtividade esperada para determinada região e as densidades de adultos capturados em armadilhas com feromônio e o número de ovos presentes nos ponteiros e frutos. Assim, estaria sendo estabelecido o número referencial de insetos nas armadilhas para a liberação do inimigo natural como tática de controle da praga. Todavia, pesquisas futuras deverão ser conduzidas para validar a utilização desta técnica visando utilização de parasitóides de ovos.

\section{AGRADECIMENTOS}

\section{Ao Leandro Mafra (ISCA} Tecnologias Ltda) pela concessão das armadilhas e septos de feromônio; ao Douglas R. Bizari, Gislaine Manente Martucci, José Luiz da Silva, Júlio César Mássimo, Luís Carlos de Souza Amorim, Nilton de Araújo Junior, Renan Gravena, Willian Morais Char e Zelinda Marconato Gravena (Gravena ManEcol Ltda) pelo suporte técnico e financiamento da pesquisa; ao José Nelson Mallmann, Valdecir Pereira e Alex de Oliveira (Produtores) pela concessão das áreas comerciais; à Andreza C. dos Santos, Bibiane C. dos Santos, Edson Godoy, Daiane de Oliveira e Viviane de Oliveira Lima (Inspetores de pragas) pelo auxílio nas avaliações.

\section{REFERÊNCIAS}

AGRIANUAL. 2002. Anuário da agricultura brasileira. São Paulo: FNP - Consultoria \& Comércio. p. 506-516.

BENTO JMS. 2000. Controle de insetos por comportamento: feromônios. In: GUEDES JC; COSTA ID; CASTIGLIONI E. Bases e técnicas do manejo de insetos. Santa Maria: UFSM/ CCR/DFS, p. 85-97.

CAFFARINI PM; FOLCIAAM; PANZARDI SR; PÉREZ A. 1999. Incidencia de bajos niveles de daño foliar de Tuta absoluta (Meyrick) en tomate. Bol. San. Veg. Plagas 25: 75-78.

EIRAS AE; FERRARA FAA; VILELA EF; PICANÇO MC; DJAN GN; ATYGALLEAB; FRIGHETO RTS. 1995. Efeito da altura da armadilha contendo o feromônio sexual sintético de Scrobipalpuloides absoluta (Meyrick) sobre a captura de adultos em tomateiro industrial. In: CONGRESSO BRASILEIRO DE ENTOMOLOGIA, 15. Resumos... Caxambu. p. 658 . 
ESPINOSA W. 1991. Manual de produção de tomate industrial no Vale do São Francisco. Brasília: IICA, Escritório do Brasil. 301 p.

GOMIDE EVA; VILELA EF; PICANÇO M 2001. Comparação de procedimentos de amostragem de Tuta absoluta (Meyrick) (Lepidoptera: Gelechiidae) em tomateiro estaqueado. Neotrop. Entomol. 30: 697-705.

GRAVENA S. 1984. Manejo Integrado de Pragas do Tomateiro. In: CONGRESSO BRASILEIRO DE OLERICULTURA, 24. Anais... Jaboticabal: FUNEP. p. 129-149.

GRAVENA S. 1991. Encontro nacional de produção e abastecimento de tomate, 2. ed. Jaboticabal: FUNEP. p. 105-157.

GRAVENA S; BENVENGA SR. 2003. Manual prático para manejo de pragas do tomate. Jaboticabal: Gravena. 143 p.

GUEDES JVC; DEQUECH STB; RIBEIRO ALP. 1996. Eficiência de armadilhas na captura da traça-do-tomateiro (Scrobipalpuloides absoluta) (Meyrick, 1917), com utilização de feromônio sexual, em estufa plástica. Ciênc. Rur. 26: 143-145.

HAJI FNP; OLIVEIRA CAV; AMORIM NETO MS; BATISTA JGS. 1998. Flutuação populacional da traça do tomateiro, no submédio São Francisco. Pesq. Agropec. Bras. 23: 7-14.

HAJI FNP; PARRA JRP; SILVA JP; BATISTA JGS. 1988. Biologia da traça-do-tomateiro em condições de laboratório. Pesq. Agropec. Bras. 23: 107-110.
MARQUES IMR; ALVES SB. 1996. Efeito de Bacillus thuringiensis Berl. var. kurstaki sobre Scrobipalpuloides absoluta Meyer (Lepidoptera: Gelechiidae). An. Soc. Entomol. Brasil 25: 39-45.

MOREIRA LA; PICANÇO MC; CASALI VWD. 1997. Injúrias de Tuta absoluta Meyrick (Lepidoptera: Gelechiidae) em tomateiros. In CONGRESSO BRASILEIRO DE ENTOMOLOGIA, 16. Resumos... Salvador. p. 332

OMOTO C. 2000. Modo de ação de inseticidas e resistência de insetos a inseticidas. In: GUEDES JC; COSTA ID; CASTIGLIONI E. Bases e técnicas do manejo de insetos. Santa Maria: UFSM/CCR/DFS. p. 31-50.

PICANÇO M; FALEIRO FG; PALLINI FILHO A; MATIOLI AL. 1997. Perdas na produtividade do tomateiro em sistemas alternativos de controle fitossanitário. Hortic. Bras. 15: 8891.

PICANÇO M; GUEDES RNC; LEITE GLD; FONTES PCR; SILVA EA. 1995. Incidência de Scrobipalpuloides absoluta (Meyrick) (Lepidoptera: Gelechiidae) em tomateiro sob diferentes sistemas de tutoramento e controle químico de pragas. Hortic. Bras. 13: 180-183.

REGO FILHO LM. 1992. Bioecologia e controle integrado de Liriomyza sativae Blanchard, 1938 (Diptera: Agromyzidae) "minador de folhas" do tomateiro, no Estado do Rio de Janeiro. Rio de Janeiro: Universidade Federal Rural. 132 p. (Dissertação mestrado).
RUPPEL RF. 1983. Cumulative insect-days as an index of crop protection. J. Econ. Entomol. 76: 375-377.

SOUZA JC; REIS PR; SALGADO LO. 1992. Traça-do-tomateiro: histórico, reconhecimento, biologia, prejuízos e controle. Belo Horizonte: EPAMIG. 19 p. (Boletim Técnico, 38).

TORRES JB; FARIA CA; EVANGELISTA JUNIOR WS; PRATISSOLI D. 2001. Withinplant distribution of the leaf miner Tuta absoluta (Meyrick) immatures in processing tomatoes, with notes on plant phenology. Int. J. Pest Manage. 47: 173-178.

UCHOA-FERNANDES MA; VILELA EF. 1994. Field trapping of the tomato worm, Scrobipalpuloides absoluta (Meyrick) (Lepidoptera: Gelechiidae) using virgin females. An. Soc. Entomol. Brasil 23: 271-276.

VARGAS HC. 1970. Observaciones sobre la biologia y enemigos naturales de la polilla del tomate, Gnorimoschema absoluta (Meyer.) (Lepidoptera: Gelechiidae). Idesia 1: 75-110.

VILELA EF. 1997. Identificação do feromônio sexual da traça do tomateiro, Tuta absoluta (Meyrick), e experiências de seu emprego no Brasil. In: CONGRESSOBRASILEIRODEENTOMOLOGIA, 16. Resumos... Salvador. p. 12.

VILELA EF; FERRARA FAA; PICANCO MC; EIRAS AE; JHAM GN; ATYGALLE AB; FRIGHETTO RTS. 1995. Eficiência de captura de traça do tomateiro Scrobipalpuloides absoluta (Meyrick) empregando o feromônio sexual sintético em tomateiro estaqueado. In: CONGRESSO BRASILEIRO DE ENTOMOLOGIA, 15. Resumos... Caxambu. p. 613 